\title{
Recognition of rotor damages in a DC motor using acoustic signals
}

\author{
A. GŁOWACZ* and Z. GŁOWACZ \\ AGH University of Science and Technology, Faculty of Electrical Engineering, Automatics, Computer Science and Biomedical Engineering, \\ 30 Mickiewicza Av., 30-059 Krakow, Poland
}

\begin{abstract}
Diagnosis of electrical direct current motors is essential for industrial plants. The emphasis is put on the development of diagnostic methods of solutions for capturing, processing and recognition of diagnostic signals. This paper presents a technique of early fault diagnosis of a DC motor. The proposed approach is based on acoustic signals. A real-world data of the DC motor were used in the analysis. The work provides an original feature extraction method called the shortened method of frequencies selection (SMoFS-15). The obtained results of the presented analysis show that the early fault diagnostic method can be used for monitoring electrical DC motors. The proposed method can also support other fault diagnosis methods based on thermal, current, and vibration signals.
\end{abstract}

Key words: acoustic signal, motor, machine, fault diagnosis, recognition.

\section{Introduction}

An early diagnosis of abnormal states of electrical motors allows industrial plants to avoid heavy economic losses involved with halted production and replacement of damaged machines. A DC motor is cheap and easy to control, which is why it was chosen for analysis. To keep an electrical motor in the best condition, the methods of fault diagnosis are developed. The objective of fault diagnosis methods is to make a decision whether a fault has occurred or not. Some actions such as repair, maintenance, and other operations should be done if a fault has occurred [1, 2]. Proper testing of electric motors is a difficult task. The problems related to diagnostic of electrical motors and electric equipments are widely discussed in the literature. The different types of motor faults, such as rotor electrical faults, stator faults, and rotor mechanical faults are described in the literature [2].

A lot of diagnostic techniques use current signals. Diagnostics of a separately-excited DC motor were presented [3]. The method of current measurement in the rotor cage bars of a prototype induction motor was also developed [4]. Current-based bearing diagnostic feature for induction motors was discussed in the literature [5]. A diagnostic model for longwall conveyor engines was described [6]. A simulation language of discrete-continuous electrical systems was discussed [7]. Fault diagnosis of motors based on thermal images was developed. The concept of a thermal model of the electromagnetic circuit of rotating electrical machines was presented [8]. Induction motor inter-turn fault detection using thermal imaging was shown [9]. Diagnostics of electric equipments by means of thermovision were developed in the literature [10]. Diagnostics of single-phase induction motor using thermal imaging were discussed [11]. Segmented infrared image analysis for rotating machinery was proposed [12]. Early detection of spontaneous combustion disasters was also described [13]. Selected methods

*e-mail: adglow@agh.edu.pl of thermal image analysis in Matlab were presented [14]. Infrared thermography of electrical installations was described [15]. Many fault diagnostic techniques based on vibration signals were developed. Progress on diagnosis of hybrid failures in gear transmission systems was presented [16]. Bi-dimensional decomposition applied to vibration signals of rolling bearing was shown [17]. Bearing fault diagnosis for induction motors using vibration signals was described [18]. Fault diagnosis of rotating machinery was discussed [19]. Influence of disc processing technology on the vibration level of a chipper was presented [20]. Evaluation of the state of rolling bearings was analysed [21, 22]. Application of vibroacoustic fault diagnosis to evaluation of rail brake disc was presented [23]. Diagnosis of IC engine valve clearance was discussed [24]. Vibroacoustic measurements applied to gear pumps were described [25]. Detection of gear cracks in a gearbox was shown [26].

Techniques based on acoustic signals of machines were presented recently. Influence of parameters and power signals on sound quality was presented [27]. Condition monitoring based on acoustic emission was described [28]. A system for identifying technical condition of combustion engine was discussed [29, 30]. Measurements of noise in CNC machines were described [31]. Monitoring of noise sources of CNC machine tools through acoustic holography methods was presented [32]. Descriptors of acoustic emission signals generated by partial discharges were discussed [33]. Automatic gear and bearing fault localization using vibration and acoustic signals was developed [34]. Bearing fault diagnosis using acoustic emission sensors was presented [35]. Recognition of acoustic signals of synchronous motors was described [36]. Methodology for fault detection in induction motors was presented [37]. Diagnostics of a DC machine using symlet wavelet transform were discussed [38]. Fault diagnostics of a loaded synchronous motor and three-phase induction motors were developed [39, 40]. Diagnostic features for condition monitoring of hypoid gear was shown [41]. Roller bearing acoustic signature extraction using wavelet transform was presented [42]. A signal processing 
approach for bearing fault diagnosis using AE sensors was described [43]. Multi-scale morphology analysis of acoustic emission signal for bearing fault was discussed [44].

The advantage of techniques based on acoustic signals is the low price of microphones. However, for these techniques there is problem with noise produced by environment, for example the noise of other motors.

This paper deals with a technique of fault diagnosis of a DC motor, based on acoustic signals. The proposed technique uses the shortened method of frequencies selection (SMoFS-15), linear discriminant analysis (LDA), and the nearest neighbour (NN) and nearest mean (NM) algorithms. The paper is subdivided into sections: section 1 contains an introduction and the literature survey, section 2 presents the proposed technique of fault diagnosis based on acoustic signals of the DC motor, section 3 puts forth the results of the analysis of the proposed technique, and section 4 concludes the findings.

\section{Proposed technique of fault diagnosis based on acoustic signal of the DC motor}

In the considered technique, healthy and faulty states of the motor were used to extract diagnostic information. The proposed technique of fault diagnosis contained two processes: a pattern creation process and an identification process (Fig. 1). The first of them used training samples and the second one used test samples of acoustic signals. Samples were recorded with the use of a sound card and a microphone (Fig. 2). The fault detection methods based on comparison of amplitude-frequency

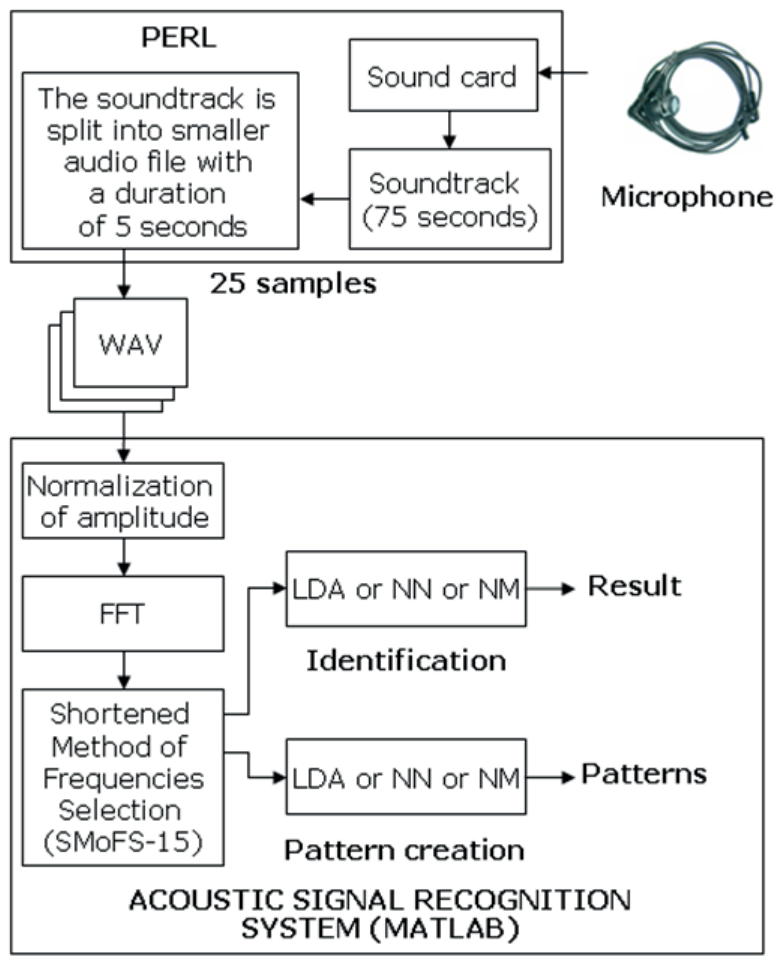

Fig. 1. Recognition of acoustic signal of the DC motor using SMoFS-15, LDA, NN, and NM

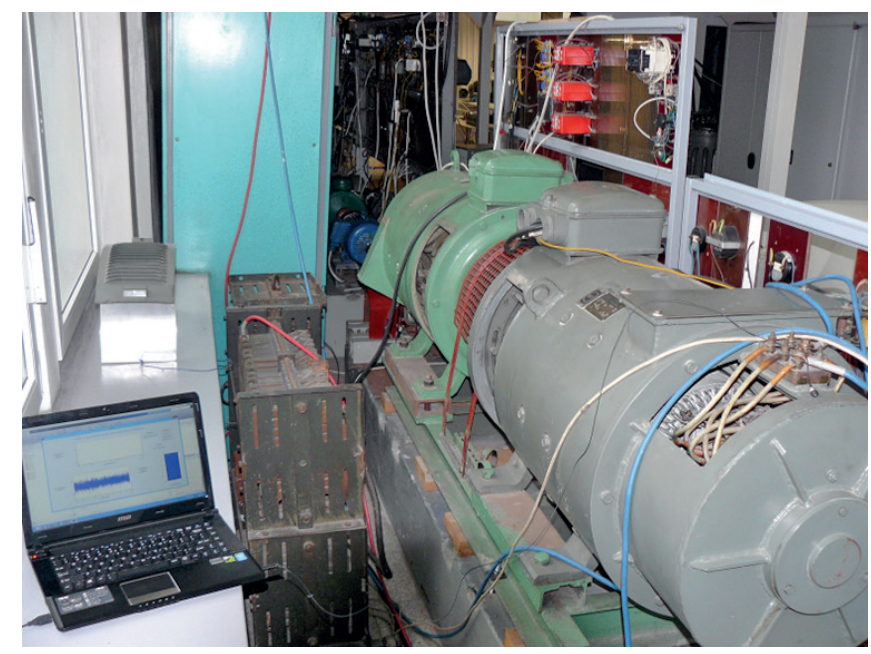

Fig. 2. Computer, microphone, and the analyzed DC motor

spectra of "healthy" and "faulty" mechanical or electrical systems depend on the measurement accuracy. The measurement accuracy depended on the sound card, the microphone, the set-up of the microphone, and the laboratory conditions. Most computers made today are equipped with good sound cards. The best microphone for this application was a condenser microphone, as its frequency response was $20 \mathrm{~Hz}-20 \mathrm{kHz}$. It was essential to obtain a high quality fault diagnosis. The microphone was installed in front of the machine (Fig. 2).

In the laboratory, one motor was operating. Therefore, the problem of recognition of multiple acoustic signals was omitted. The authors used Olympus TP-7 and Zalman ZM-MIC1 condenser microphones, because of their low cost. The format of the obtained audio track was characterized as follows: 16-bit depth, number of channels - mono, sampling rate $-44100 \mathrm{~Hz}$, WAVE PCM format. The recorded signal was processed into a soundtrack and next, into smaller audio files with a duration of 5 seconds. The audio signal was normalized (in the range of $[-1,1])$ and then, the frequency spectrum was calculated (Hamming window - 32768) [45]. The obtained spectrum was processed by the shortened method of frequencies selection (SMoFS-15). The SMoFS-15 was described in the further part of the paper (section 2.1). The results of the SMoFS-15 method were selected amplitudes of acoustic pressure. These features (amplitudes of acoustic pressure) were classified by the LDA, $\mathrm{NN}$, and NM. The patterns were based on training samples. In the proposed approach, LDA used the patterns of various classes separated by the hyperplanes. The NN and NM used feature vectors. The final results of the identification process were the results of recognized classes. The results of recognized classes were based on test samples.

\subsection{Shortened method of frequencies selection (SMoFS-15).}

The obtained FFT spectrum was processed by the shortened method of frequencies selection (SMoFS-15). A block diagram of the proposed feature extraction method was shown in Fig. 3. The parameter $t$ depended on the number of analysed states of the DC motor and the number of frequency components - the 


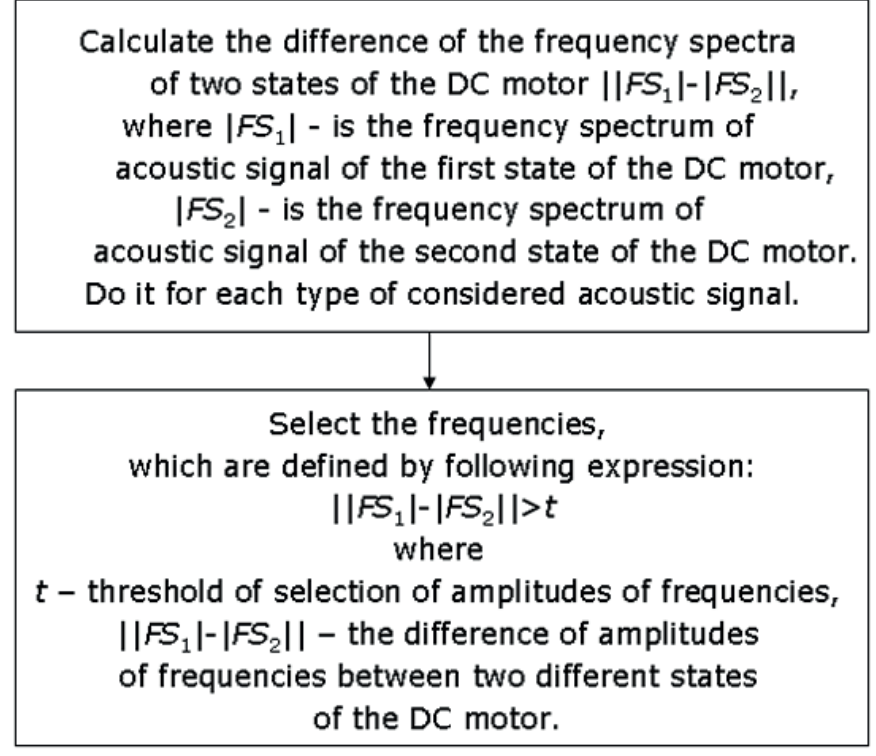

Fig. 3. Block diagram of the shortened method of frequencies selection (SMoFS-15)

NoF (number of frequency components) parameter. Too small of a number of frequency components could cause errors. The differences between the selected frequency components could have different values (e.g. the difference between state $X$ and state $Y$ had maximum amplitudes for frequency components $120,240,360,480,600 \mathrm{~Hz}$; the difference between state $X$ and state $Z$ had maximum amplitudes for frequency components $150,300,450,600,750 \mathrm{~Hz}$; the difference between state $Y$ and state $\mathrm{Z}$ had maximum amplitudes for frequency components $200,400,600,800,1000 \mathrm{~Hz}$, therefore states $X, Y$, and $Z$ had one common frequency of $600 \mathrm{~Hz}$ ). However, there was a possibility that there were no common frequency components. To solve this problem, the parameter $t$ was calculated according to formulas (1) and (2). When NoF is greater than 15, the will perform loop calculations (2). If NoF is smaller or equal to 15 , SMoFS-15 finishes its calculations. The NoF threshold has been selected as 15 . Of course, the authors could have selected another $N o F$ threshold, for example 16 , but in that case, finally the feature vector would have had 1-16 features. So, this parameter should be selected experimentally. In the authors' opinion, NoF threshold equal to 15 is good, because operating on too many features is not optimal for the next step, which is classification.

$$
\begin{gathered}
t=\frac{\sum_{N o F=1}^{N o F}\left\|F S_{1}|-| F S_{2}\right\|}{N o F}, \\
N o F \leq 15,
\end{gathered}
$$

where: $t$ - threshold of selection amplitudes of acoustic pressure (depending on $\mathrm{NoF}$ and the analysed acoustic signal), $\mathrm{NoF}$ - number of frequency components (initially $N o F=16384$ ), as 16384 was the number of frequency components obtained using the FFT.
Amplitudes of acoustic pressure of the DC motor's acoustic signal, calculated by the SMoFS-15, were used to form feature vectors. Finally, the obtained feature vector had 1-15 features. The difference between the spectrum of acoustic signal of a healthy DC motor and the spectrum of acoustic signal of a DC motor with 6 shorted rotor coils was presented in Fig. 4. (SMoFS-15 finished the calculations, as $N o F<15$ ). The SMoFS-15 performed 1 iteration more when $t=0.0051$ and $N o F=30$, because $N o F>15$ (Fig. 5). SMoFS-15 selected

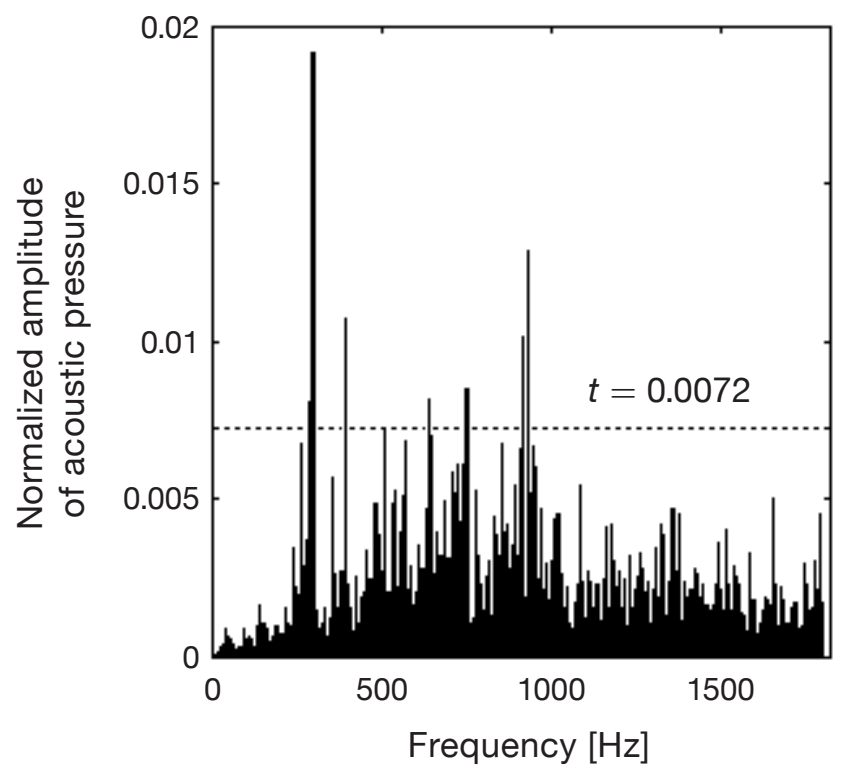

Fig. 4. The difference between spectrum of acoustic signal of the healthy DC motor and spectrum of acoustic signal of the DC motor with 6 shorted rotor coils (rotor speed $=400 \mathrm{rpm}, t=0.0072$, $N o F=8, S M o F S-15$ finished calculations)

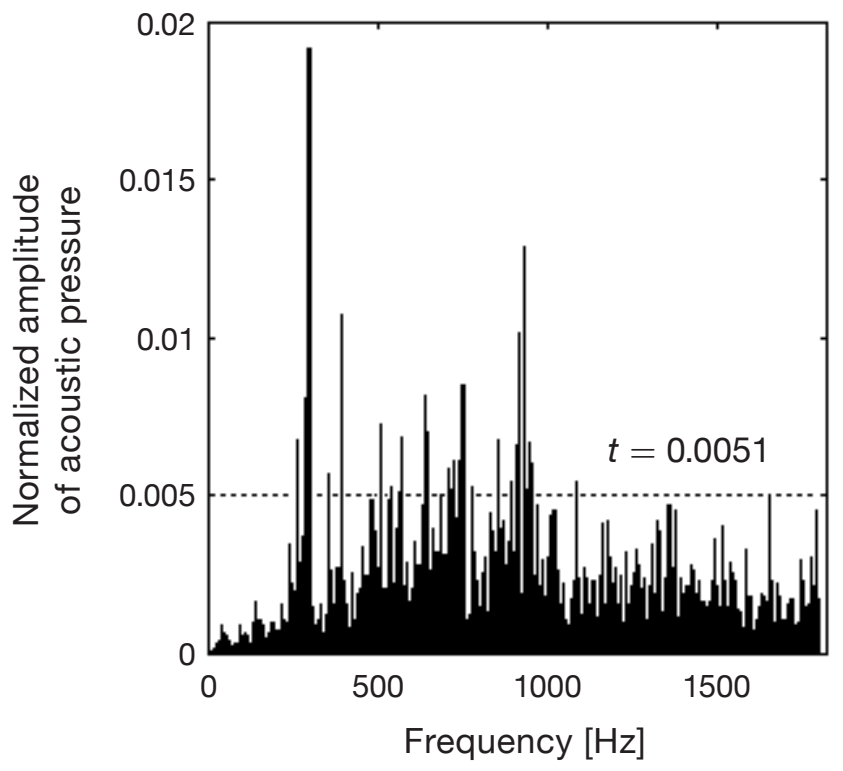

Fig. 5. The difference between the spectrum of acoustic signal of the healthy DC motor and the spectrum of acoustic signal of the DC motor with 6 shorted rotor coils (rotor speed $=400 \mathrm{rpm}, t=0.0051$, $N o F=30$, SMoFS-15 does 1 iteration more, because $N o F>15$ ) 


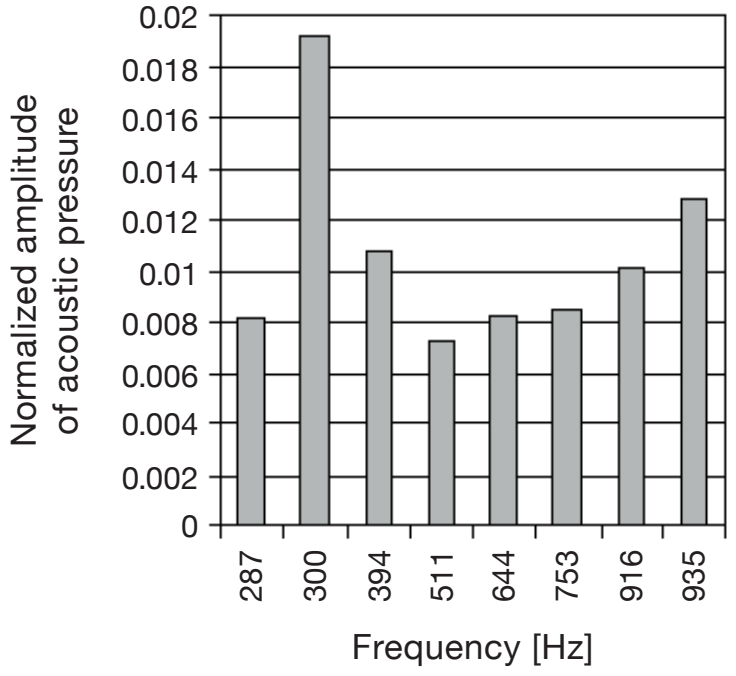

Fig. 6. Selected frequency components for difference between the spectrum of acoustic signal of the healthy DC motor and the spectrum of acoustic signal of the DC motor with 6 shorted rotor coils using SMoFS-15 (rotor speed $=400 \mathrm{rpm})$

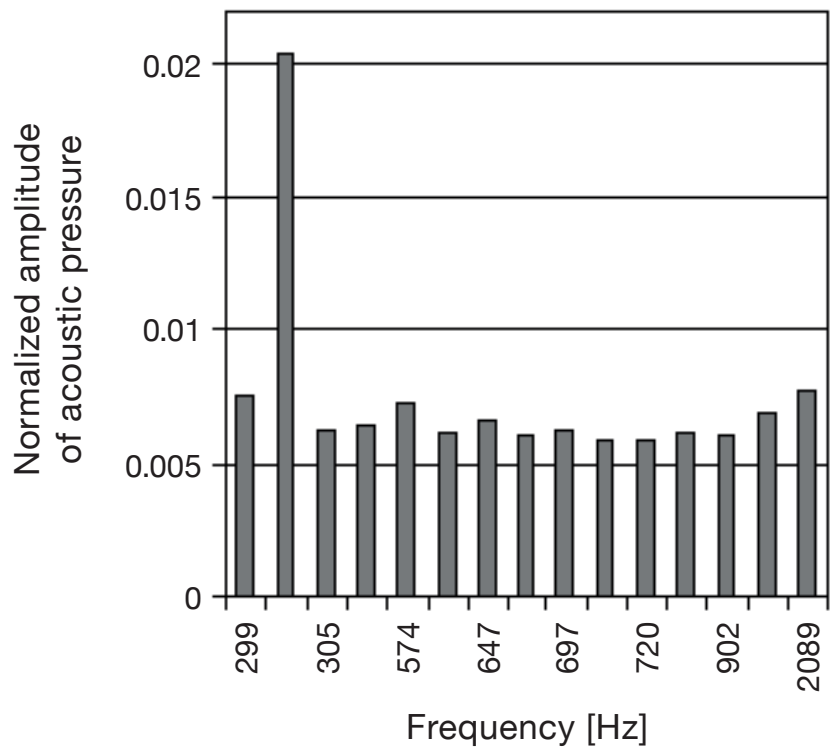

Fig. 8. Selected frequency components for difference between the spectrum of acoustic signal of the DC motor with 6 shorted rotor coils and the spectrum of acoustic signal of the DC motor with broken coil and 6 shorted rotor coils using SMoFS-15 (rotor speed $=400 \mathrm{rpm}$ )

the frequency components for differences between spectra of acoustic signals of healthy and faulty DC motors (Figs. 6-8). One frequency $(300 \mathrm{~Hz})$ was common for the analysed states of the DC motor (Fig. 9). The feature vector consisted of a selected amplitude of acoustic pressure ( $300 \mathrm{~Hz}$ frequency). This vector was used in the classification step (Fig. 9).

2.2. Analysed classifiers. The methods responsible for making decisions were used in the classification step. The classification of feature vectors was described in the literature [46-63]. In the presented approach, single-element feature vectors were

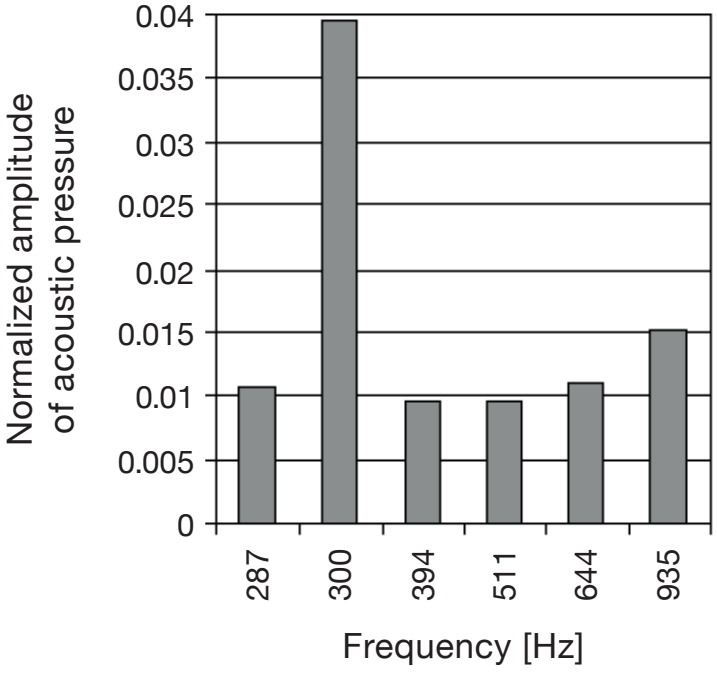

Fig. 7. Selected frequency components for difference between the spectrum of acoustic signal of the healthy DC motor and the spectrum of acoustic signal of the DC motor with broken coil and 6 shorted rotor coils using SMoFS-15 (rotor speed $=400 \mathrm{rpm}$ )

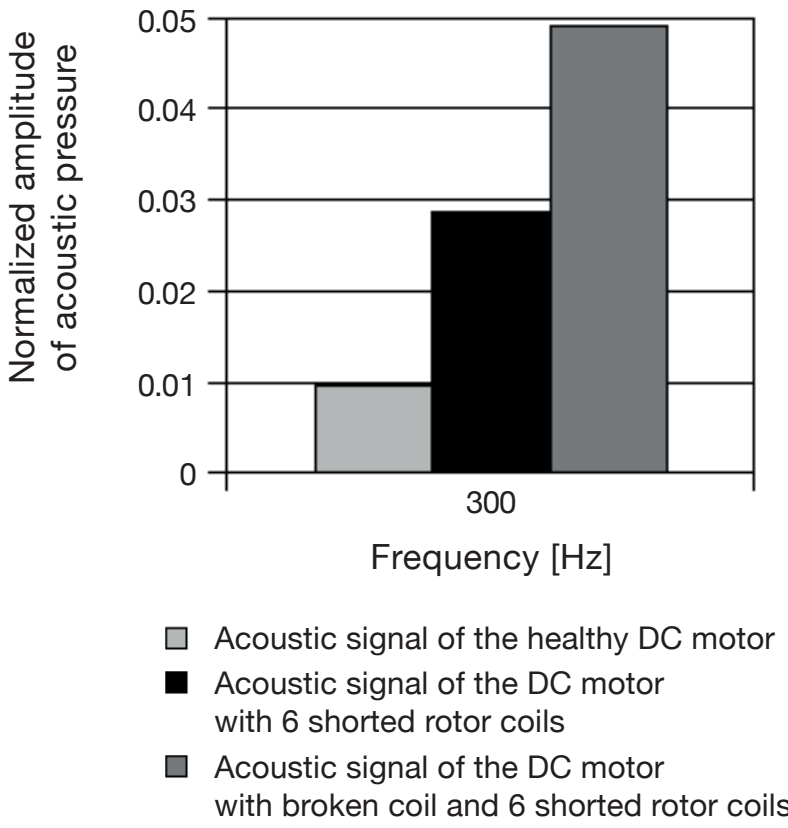

Fig. 9. Common frequency for the analysed states of the DC motor $(300 \mathrm{~Hz})$ using SMoFS-15

obtained. For this reason, the step of classification could be selected in various ways. Most of the obtained feature vectors were separable linearly, therefore many classification methods could be used to solve problems such as: fuzzy logic [46], clustering method [47], nearest mean, k-nearest neighbour classifier $[36,48,49]$, neural network [50-55], naive Bayes classifier [56], classifier based on word coding [36], linear discriminant analysis (LDA) [57, 58], support vector machine [59, 60], rules based on the theory of rough sets [61], Gaussian mixture models (GMM) $[62,63]$. The authors decided to analyse LDA, nearest neighbour $(\mathrm{NN})$ classifier, and the nearest mean (NM) classi- 
fier, because they had small computational complexity. LDA calculated the ratio of between-class variance to the within-class variance $(\operatorname{Det}|B| / \operatorname{Det}|W|)$. The Between-class scatter matrix was expressed by the following formula:

$$
B=\sum_{k=1}^{c}\left(\mu_{k}-\mu\right)\left(\mu_{k}-\mu\right)^{T},
$$

where $\mu$ denotes the mean of all training sets, $\mathbf{x}, \boldsymbol{\mu}$ - vectors of dimensions equal to the selected number of common frequency components.

The within-class scatter matrix was defined as follows:

$$
W=\sum_{k=1}^{c} \sum_{i=1}^{N_{k}}\left(\mu_{i}^{k}-\mu_{k}\right)\left(\mu_{i}^{k}-\mu_{k}\right)^{T},
$$

where $\mu_{k}$ denotes the mean of class $k, x_{i}^{k}$ is the sample with the index $i$ of class $k, c$ denotes the number of classes of training sets, and $N_{k}$ is the number of samples of class $k$.

The separability of the classes was dependent on the calculated ratio $(\operatorname{Det}|B| / \operatorname{Det}|W|)$. LDA is discussed in greater detail in the literature $[57,58]$.

The Nearest Neighbour classifier measured the least distances between all training samples. The classifier selected the most similar class to test samples. The Nearest Mean classifier used arithmetic mean instead of training sample. The remaining steps were the same as in the case of using the NN. The authors used Manhattan distance for these two classifiers (NN, NM). More about the nearest neighbour classifier is available in the literature $[36,48]$.

\section{Analysis of acoustic signals of the DC motor}

In the conducted analysis, acoustic signals from the DC motor were employed to identify states of the motor. States of the DC motor were as follows: healthy DC motor, DC motor with 6 shorted rotor coils, and DC motor with broken coil and 6 shorted rotor coils. The DC motor had a rotor speed of $400 \mathrm{rpm}$ and a motor power $P=13000 \mathrm{~W}$.

Parameters of the DC motor were as follows:

- healthy DC motor (Fig. 10): $U_{a v}=35 \mathrm{~V}, I_{a c}=46.5 \mathrm{~A}$, $U_{e v}=159.6 \mathrm{~V}, I_{e c}=2.5 \mathrm{~A}$,

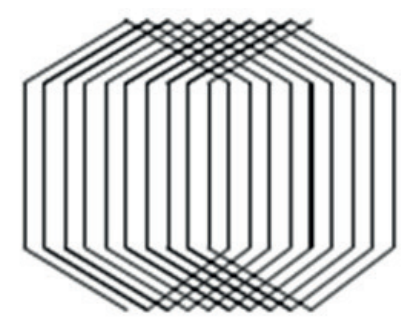

Fig. 10. Scheme of rotor windings of the healthy DC motor
- DC motor with 6 shorted rotor coils (Fig. 11): $U_{a v}=34 \mathrm{~V}$, $I_{a c}=45.75 \mathrm{~A}, U_{e v}=162.8 \mathrm{~V}, I_{e c}=2.5 \mathrm{~A}, I_{c s c}=83 \mathrm{~A}$,

\section{SHORT CIRCUIT}

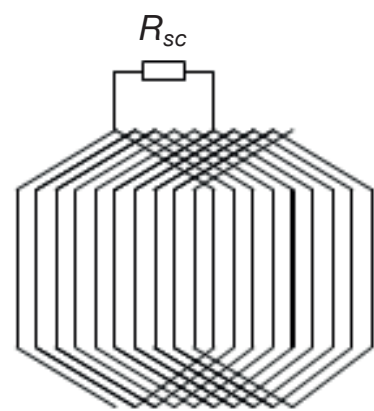

Fig. 11. Scheme of rotor windings of the DC motor with 6 shorted coils

- DC motor with broken coil and 6 shorted rotor coils (Fig. 12): $U_{a v}=34 \mathrm{~V}, I_{a c}=46.25 \mathrm{~A}, U_{e v}=165.3 \mathrm{~V}$, $I_{c s c}=2.5 \mathrm{~A}, I_{s c}=81 \mathrm{~A}$,

\section{SHORT CIRCUIT}

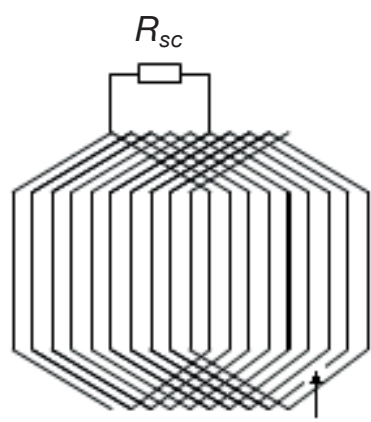

BROKEN COIL

Fig. 12. Scheme of rotor windings of the DC motor with broken coil and 6 shorted coils

where: $U_{a v}$ - armature voltage of the DC motor, $I_{a c}$ - armature current of the DC motor, $U_{e v}$ - excitation voltage of the DC motor, $I_{e c}$ - excitation current of the DC motor, $I_{c s c}-$ current of the short-circuit.

Six loops of rotor coils were shorted using resistance $R_{s c}=0.085 \mathrm{~m} \Omega$. This resistance was connected to the rotor coils of the motor.

Twelve training samples and 75 test samples were used in the analysis. Samples had a duration of 5 seconds each. The mentioned samples were used to evaluate efficiency of recognition of the acoustic signal. This efficiency was expressed by:

$$
E=\frac{N P R T S}{N A T S} 100 \%,
$$

where: NPRTS - number of properly recognized test samples, $N A T S$ - number of all samples used for identification, $E$ - efficiency of recognition of acoustic signal. 
The total efficiency of recognition of acoustic signal was defined as:

$$
T E R A S=\frac{E_{h}+E_{s}+E_{s b}}{3},
$$

where: TERAS - Total efficiency of recognition of acoustic signal, $E_{h}$ - efficiency of recognition of acoustic signal of the healthy DC motor, $E_{s}$ - efficiency of recognition of acoustic signal of the DC motor with 6 shorted rotor coils, $E_{s b}-$ efficiency of recognition of acoustic signal of the DC motor with broken coil and 6 shorted rotor coils.

The results of recognition of acoustic signal of the DC motor with the use of SMoFS-15 and LDA were presented in Table 1. The value of $E$ was in the range of $76-100 \%$ and the value of TERAS was $84 \%$.

Table 1

Results of recognition of acoustic signal of the DC motor with the use of SMoFS-15 and linear discriminant analysis (LDA)

\begin{tabular}{|l|c|}
\hline State of the DC motor & $E[\%]$ \\
\hline Healthy DC motor & 76 \\
\hline Motor with 6 shorted rotor coils & 76 \\
\hline Motor with broken coil and 6 shorted rotor coils & 100 \\
\hline & $T E R A S[\%]$ \\
\hline 3 analysed states of motor & 84 \\
\hline
\end{tabular}

The results of recognition of acoustic signal of the DC motor with the use of SMoFS-15 and NN were presented in Table 2. The value of $E$ was in the range of 56-96\% and the value of TERAS was $70.66 \%$.

Table 2

Results of recognition of acoustic signal of the DC motor with the use of SMoFS-15, nearest neighbour (NN)

\begin{tabular}{|l|c|}
\hline State of the DC motor & $E[\%]$ \\
\hline Healthy DC motor & 60 \\
\hline Motor with 6 shorted rotor coils & 56 \\
\hline Motor with broken coil and 6 shorted rotor coils & 96 \\
\hline & TERAS [\%] \\
\hline 3 analysed states of motor & 70.66 \\
\hline
\end{tabular}

The results of recognition of acoustic signal of the DC motor with the use of SMoFS-15 and NM were presented in Table 3. The Value of $E$ was in the range of $36-100 \%$ and the value of TERAS was $70.66 \%$.
Table 3

Results of recognition of acoustic signal of the DC motor with the use of SMoFS-15, Nearest Mean (NM)

\begin{tabular}{|l|l|}
\hline State of the DC motor & $E[\%]$ \\
\hline Healthy DC motor & 76 \\
\hline Motor with 6 shorted rotor coils & 36 \\
\hline Motor with broken coil and 6 shorted rotor coils & 100 \\
\hline & TERAS [\%] \\
\hline 3 analysed states of motor & 70.66 \\
\hline
\end{tabular}

\section{Conclusions}

In this approach, the authors used real-world data. Measurements were carried out with the use of capacitor microphone for a healthy DC motor and for a DC motor with faults. The paper presented the technique of fault diagnosis of a DC motor. The technique was based on the recognition of acoustic signals. The work provided an original feature extraction method called SMoFS-15. It was shown that by using the proposed method (SMoFS-15) good results of recognition can be obtained. The total efficiency of recognition of acoustic signal of the DC motor was equal to $84 \%$ for the linear discriminant analysis. It was surprising that the nearest neighbour and the nearest mean classifiers had lower efficiency of recognition than LDA. The presented technique finds an application in early fault diagnosis of DC motors of the same type and size. If the patterns are properly prepared, other electric machines can be diagnosed using the proposed technique. The presented technique of fault diagnosis is not expensive, as the computers together with a microphone cost around $\$ 300$. The proposed technique can also support other fault diagnosis techniques based on thermal, current, and vibration signals. Future diagnostic systems will use the mentioned signals to make decisions about the state of a machine. In this way, more reliable diagnostic systems for rotating electrical machines will be used in the industry.

Acknowledgements. This work has been supported by AGH University of Science and Technology, grant no. 11.11.120.612 (Adam Głowacz) and grant no. 11.11.120.354. (Zygfryd Głowacz).

\section{REFERENCES}

[1] K. Patan, "Artificial neural networks for the modelling and fault diagnosis of technical processes", Lecture Notes in Control and Information Sciences 377, 1-206 (2008).

[2] H. Henao et al., "Trends in fault diagnosis for electrical machines a review of diagnostic techniques", IEEE Industrial Electronics Magazine 8 (2), 31-42 (2014).

[3] W. Głowacz and Z. Głowacz, "Diagnostics of separately excited DC motor based on analysis and recognition of signals using FFT and Bayes classifier", Archives of Electrical Engineering 64 (1), 29-35 (2015). 
[4] M. Sulowicz, K. Weinreb, R. Mielnik, T. Zywczak, and M. Jaraczewski, "The method of current measurement in the rotor cage bars of prototype induction motor with the use of Rogowski coils", International Conference on Information and Digital Technologies (IDT), 357-365 (2015).

[5] T. Ciszewski, L. Gelman, and L. Swedrowski, "Current-based higher-order spectral covariance as a bearing diagnostic feature for induction motors", Insight 58 (8), 431-434 (2016).

[6] M. Michalak, B. Sikora, and J. Sobczyk, "Diagnostic model for longwall conveyor engines", Man-Machine Interactions 4 ICMMI 391, 437-448 (2016).

[7] Z. Głowacz and A. Głowacz, "Simulation language for analysis of discrete-continuous electrical systems (SESL2)", Proceedings of the 26th IASTED International Conference on Modelling, Identification, and Control, Innsbruck, Austria, 94-99 (2007).

[8] B. Będkowski and J. Madej, "The innovative design concept of thermal model for the calculation of the electromagnetic circuit of rotating electrical machines", Eksploatacja i Niezawodność - Maintenance and Reliability 17 (4), 481-486 (2015).

[9] G. Singh, T.C.A. Kumar, and V.N.A. Naikan, "Induction motor inter turn fault detection using infrared thermographic analysis", Infrared Physics \& Technology 77, 277-282 (2016).

[10] M. Sebok, M. Gutten, and M. Kucera, "Diagnostics of electric equipments by means of thermovision", Przeglad Elektrotechniczny 87 (10), 313-317 (2011).

[11] A. Głowacz and Z. Głowacz, "Diagnostics of stator faults of the single-phase induction motor using thermal images, MoASoS and selected classifiers", Measurement 93, 86-93 (2016).

[12] L.X. Duan, M.C. Yao, J.J. Wang, T.B. Bai, L.B. Zhang, "Segmented infrared image analysis for rotating machinery fault diagnosis", Infrared Physics \& Technology 77, 267-276 (2016).

[13] H. Liu, Z.X. Wang, J. Zhong, and Z.W. Xie, "Early detection of spontaneous combustion disaster of sulphide ore stockpiles", Tehnicki Vjesnik - Technical Gazette 22 (6), 1579-1587 (2015).

[14] R. Koprowski, "Some selected quantitative methods of thermal image analysis in Matlab", Journal of Biophotonics 9 (5), 510-520 (2016).

[15] H. Glavas, L. Jozsa, and T. Baric, "Infrared thermography in energy audit of electrical installations", Tehnicki Vjesnik - Technical Gazette 23 (5), 1533-1539 (2016).

[16] Z.X. Li, Y. Jiang, C. Hu, and Z. Peng, "Recent progress on decoupling diagnosis of hybrid failures in gear transmission systems using vibration sensor signal: A review", Measurement 90 , 4-19 (2016)

[17] Y. Jiang, Z.X. Li, C. Zhang, C. Hu, and Z. Peng, "On the bi-dimensional variational decomposition applied to nonstationary vibration signals for rolling bearing crack detection in coal cutters", Measurement Science and Technology 27 (6), (2016).

[18] D.H. Hwang, Y.W. Youn, J.H. Sun, K.H. Choi, J.H. Lee, and Y.H. Kim, "Support vector machine based bearing fault diagnosis for induction motors using vibration signals", Journal of Electrical Engineering \& Technology 10 (4), 1558-1565 (2015).

[19] C. Li, R.V. Sanchez, G. Zurita, M. Cerrada, and D. Cabrera, "Fault diagnosis for rotating machinery using vibration measurement deep statistical feature learning", Sensors 16 (6), (2016).

[20] G.M. Krolczyk, J.B. Krolczyk, S. Legutko, and A. Hunjet, "Effect of the disc processing technology on the vibration level of the chipper during operations", Tehnicki Vjesnik - Technical Gazette 21 (2), 447-450 (2014).

[21] G. Perun and Z. Stanik, "Evaluation of state of rolling bearings mounted in vehicles with use of vibration signals", Archives of Metallurgy and Materials 60 (3), 1679-1683 (2015).
[22] Z. Stanik, G. Perun, and T. Matyja, "Effective methods for the diagnosis of vehicles rolling bearings wear and damages", Archives of Metallurgy and Materials 60 (3), 1717-1724 (2015).

[23] W. Sawczuk, "Application of vibroacoustic diagnostics to evaluation of wear of friction pads rail brake disc", Eksploatacja $i$ Niezawodność - Maintenance and Reliability 18 (4), 565-571 (2016).

[24] L. Jedlinski, J. Caban, L. Krzywonos, S. Wierzbicki, and F. Brumercik, "Application of vibration signal in the diagnosis of IC engine valve clearance", Journal of Vibroengineering 17 (1), 175-187 (2015).

[25] E. Carletti, G. Miccoli, F. Pedrielli, and G. Parise, "Vibroacoustic measurements and simulations applied to external gear pumps. An integrated simplified approach", Archives of Acoustics 41 (2), 285-296 (2016).

[26] Z.X. Li, X.P. Yan, X.P. Wang, and Z.X. Peng, "Detection of gear cracks in a complex gearbox of wind turbines using supervised bounded component analysis of vibration signals collected from multi-channel sensors", Journal of Sound and Vibration 371, 406-433 (2016).

[27] R. Lara, R. Jimenez-Romero, F. Perez-Hidalgo, and M.D. Redel-Macias, "Influence of constructive parameters and power signals on sound quality and airborne noise radiated by inverter-fed induction motors", Measurement 73, 503-514 (2015).

[28] W. Caesarendra, B. Kosasih, A.K. Tieu, H.T. Zhu, C.A.S. Moodie, and Q. Zhu, "Acoustic emission-based condition monitoring methods: Review and application for low speed slew bearing", Mechanical Systems and Signal Processing 72-73, 134-159 (2016).

[29] A. Deptuła, D. Kunderman, P. Osiński, U. Radziwanowska, and R. Włostowski, "Acoustic diagnostics applications in the study of technical condition of combustion engine", Archives of Acoustics 41 (2), 345-350 (2016).

[30] A. Deptuła, P. Osiński, and U. Radziwanowska, "Decision support system for identifying technical condition of combustion engine", Archives of Acoustics 41 (3), 449-460 (2016).

[31] D. Mika, J. Józwik, "Normative measurements of noise at CNC machines work stations", Advances in Science and Technology Research Journal 10 (30), 138-143 (2016).

[32] J. Józwik, "Identification and monitoring of noise sources of CNC machine tools by acoustic holography methods", Advances in Science and Technology Research Journal 10 (30), 127-137 (2016).

[33] M. Kunicki, A. Cichon, and S. Borucki, "Study on descriptors of acoustic emission signals generated by partial discharges under laboratory conditions and in on-site electrical power transformer", Archives of Acoustics 41 (2), 265-276 (2016).

[34] D.P. Jena, S.N. Panigrahi, "Automatic gear and bearing fault localization using vibration and acoustic signals", Applied Acoustics 98, 20-33 (2015).

[35] B. Van Hecke, J. Yoon, and D. He, "Low speed bearing fault diagnosis using acoustic emission sensors", Applied Acoustics 105, 35-44 (2016).

[36] A. Głowacz, "Recognition of acoustic signals of synchronous motors with the use of MoFS and selected classifiers", Measurement Science Review 15 (4), 167-175 (2015).

[37] P.A. Delgado-Arredondo, D. Morinigo-Sotelo, R.A. Osornio-Rios, J.G. Avina-Cervantes, H. Rostro-Gonzalez, and R.D. Romero-Troncoso, "Methodology for fault detection in induction motors via sound and vibration signals", Mechanical Systems and Signal Processing 83, 568-589 (2017). 
[38] A. Głowacz, "Diagnostics of Direct Current machine based on analysis of acoustic signals with the use of symlet wavelet transform and modified classifier based on words", Eksploatacja i Niezawodność - Maintenance and Reliability 16 (4), 554-558 (2014).

[39] A. Głowacz, "Fault diagnostics of acoustic signals of loaded synchronous motor using SMOFS-25-EXPANDED and selected classifiers", Tehnicki Vjesnik - Technical Gazette 23 (5), 1365-1372 (2016).

[40] A. Głowacz, "Recognition of acoustic signals of induction motors with the use of MSAF10 and Bayes classifier", Archives of Metallurgy and Materials 61 (1), 153-157 (2016).

[41] V. Skrickij, M. Bogdevicius, and R. Junevicius, "Diagnostic features for the condition monitoring of hypoid gear utilizing the wavelet transform", Applied Acoustics 106, 51-62 (2016).

[42] F. Hemmati, W. Orfali, and M.S. Gadala, "Roller bearing acoustic signature extraction by wavelet packet transform, applications in fault detection and size estimation", Applied Acoustics 104, 101-118 (2016)

[43] M. He, D. He, and Y.Z. Qu, "A new signal processing and feature extraction approach for bearing fault diagnosis using $\mathrm{AE}$ sensors", Journal of Failure Analysis and Prevention 16 (5), 821-827 (2016)

[44] W.J. Wang, L.L. Cui, and D.Y. Chen, "Multi-scale morphology analysis of acoustic emission signal and quantitative diagnosis for bearing fault", Acta Mechanica Sinica 32 (2), 265-272 (2016).

[45] K. Stepien, "Research on a surface texture analysis by digital signal processing methods", Tehnicki Vjesnik - Technical Gazette 21 (3), 485-493 (2014)

[46] D. Valis and K. Pietrucha-Urbanik, "Utilization of diffusion processes and fuzzy logic for vulnerability assessment", Eksploatacja i Niezawodność - Maintenance and Reliability 16 (1), 48-55 (2014).

[47] D. Valis, L. Zak, and O. Pokora, "System condition estimation based on selected tribodiagnostic data", Quality and Reliability Engineering International 32 (2), 635-645 (2016).

[48] R. Islam, S.A. Khan, and J.M. Kim, "Discriminant feature distribution analysis-based hybrid feature selection for online bearing fault diagnosis in induction motors", Journal of Sensors 2016 (2016), Article No. 7145715 (2016).

[49] P. Augustyniak, M. Smoleń, Z. Mikrut, and E. Kantoch, "Seamless tracing of human behavior using complementary wearable and house-embedded sensors", Sensors 14 (5), 7831-7856 (2014).

[50] E. Dudek-Dyduch, R. Tadeusiewicz, and A. Horzyk, "Neural network adaptation process effectiveness dependent of constant training data availability", Neurocomputing 72 (13-15), 3138-3149 (2009).

[51] J. Roj and A. Cichy, "Method of measurement of capacitance and dielectric loss factor using artificial neural networks", Measurement Science Review 15 (3), 127-131 (2015).
[52] D. Panek, A. Skalski, J. Gajda, and R. Tadeusiewicz, "Acoustic analysis assessment in speech pathology detection", International Journal of Applied Mathematics and Computer Science 25 (3), 631-643 (2015).

[53] D. Jamroz and T. Niedoba, "Application of multidimensional data visualization by means of self-organizing Kohonen maps to evaluate classification possibilities of various coal types", Archives of Mining Sciences 60 (1), 39-50 (2015).

[54] T. Hachaj and M.R. Ogiela, "Application of neural network for human actions recognition", Computational Intelligence and Intelligent Systems, ISICA, Communications in Computer and Information Science 575, 183-191 (2016).

[55] S. Jun and O. Kochan, "Investigations of thermocouple drift irregularity impact on error of their inhomogeneity correction", Measurement Science Review 14 (1), 29-34 (2014).

[56] R.H.C. Palacios, I.N. da Silva, A. Goedtel, and W.F. Godoy, "A comprehensive evaluation of intelligent classifiers for fault identification in three-phase induction motors", Electric Power Systems Research 127, 249-258 (2015).

[57] A. Yadav and A. Swetapadma, "A novel transmission line relaying scheme for fault detection and classification using wavelet transform and linear discriminant analysis", Ain Shams Engineering Journal 6 (1), 199-209 (2015).

[58] C.P. Mbo'o and K. Hameyer, "Fault diagnosis of bearing damage by means of the linear discriminant analysis of stator current features from the frequency selection", IEEE Transactions on Industry Applications 52 (5), 3861-3868 (2016).

[59] J. Jaworek-Korjakowska and P. Kleczek, "Automatic classification of specific melanocytic lesions using artificial intelligence", BioMed Research International, Article No. 8934242 (2016).

[60] D. Wilk-Kolodziejczyk, K. Regulski, and G. Gumienny, "Comparative analysis of the properties of the nodular cast iron with carbides and the austempered ductile iron with use of the machine learning and the support vector machine", International Journal of Advanced Manufacturing Technology 87 (1-4), 1077-1093 (2016).

[61] Z. Gorny, S. Kluska-Nawarecka, D. Wilk-Kolodziejczyk, and K. Regulski, "Methodology for the construction of a rule-based knowledge base enabling the selection of appropriate bronze heat treatment parameters using rough sets", Archives of Metallurgy and Materials 60 (1), 309-312 (2015).

[62] E.P. Frigieri, P.H.S. Campos, A.P. Paiva, P.P. Balestrassi, J.R. Ferreira, and C.A. Ynoguti, "A mel-frequency cepstral coefficient-based approach for surface roughness diagnosis in hard turning using acoustic signals and Gaussian mixture models", Applied Acoustics 113, 230-237 (2016).

[63] R.M. Bowen, F. Sahin, and A. Radomski, "Systemic health evaluation of RF generators using Gaussian mixture models", Computers \& Electrical Engineering 53, 13-28 (2016). 